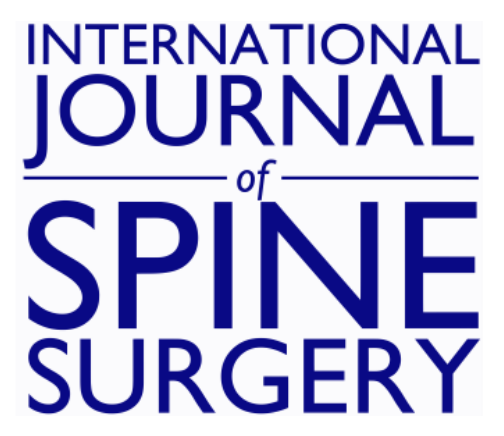

\title{
How to Select the Lower Instrumented Vertebra in Traditional Growing Rods Index Surgery
}

Federico Fusini, Javier Pizones, Lucía Moreno-Manzanaro, José Miguel Sánchez Márquez, Gloria Talavera, Nicomedes Fernández-Baíllo and Francisco Javier Sánchez Pérez-Grueso

Int J Spine Surg 2021, 15 (3) 577-584

doi: https://doi.org/10.14444/8078

http://ijssurgery.com/content/15/3/577

This information is current as of April 26, 2023.

Email Alerts Receive free email-alerts when new articles cite this article. Sign up at: http://ijssurgery.com/alerts 


\title{
How to Select the Lower Instrumented Vertebra in Traditional Growing Rods Index Surgery
}

\author{
FEDERICO, FUSINI, MD ${ }^{1}$ JAVIER PIZONES, MD, PHD, ${ }^{2}$ LUCÍA MORENO-MANZANARO, BA, ${ }^{2}$ JOSÉ \\ MIGUEL SÁNCHEZ MÁRQUEZ, MD, PHD ${ }^{2}$ GLORIA TALAVERA, MD, ${ }^{2}$ NICOMEDES FERNÁNDEZ- \\ BAÍLLO, MD ${ }^{2}$ FRANCISCO JAVIER SÁNCHEZ PÉREZ-GRUESO, MD ${ }^{2}$ \\ ${ }^{I}$ Department of Orthopaedic and Traumatology, Orthopaedic and Trauma Centre, Città della Salute e della Scienza di Torino, University of Turin, Turin, Italy, \\ ${ }^{2}$ Spine Unit, Department of Orthopedic Surgery, Hospital Universitario La Paz, Madrid, Spain
}

\begin{abstract}
Background: There are still no consensus criteria on how to select the lower instrumented vertebra (LIV) for traditional growing rods (TGRs) at index surgery. The aim was to evaluate whether the criteria used for adolescent idiopathic scoliosis fusion adapts to early onset scoliosis (EOS).

Methods: Retrospective analysis of prospectively longitudinal collected data in a consecutive cohort of patients with EOS treated with TGR, expanding from index surgery to 2 years after graduation. The LIV was analyzed regarding its relation to the stable vertebra (SV), substantially touched vertebra (STV), and not STV (NSTV). Failure of LIV selection was considered when revision surgery with distal extension was needed during follow up, due to adding on $\left(\Delta\right.$ LIV tilt $\left.>10^{\circ}\right)$.

Results: A total of 25 patients met inclusion criteria. Mean age was $8.6 \pm 3$ (at index surgery), $15.1 \pm 1.8$ (at graduation), and $17.8 \pm 1.6$ (at final follow up). The most frequent LIV at index surgery was L3 (13/25); in 13 cases, STV was selected as LIV; in 7, it was NSTV; and in 5, SV on the standard postero-anterior radiographs. During follow up, a significant increase in the mean LIV tilt $(P=.049)$ and distal junctional angle $(P=.017)$ was found. Nine of the 25 patients $(36 \%)$ developed adding on: $20 \%(1 / 5)$ of those with LIV at SV, 38.5\% (5/13) at STV, and $42.8 \%(3 / 7)$ at NSTV. Of those 9 cases of adding on, only four needed distal extension (mean LIV tilt $\left.=17.6^{\circ}\right): 2 \mathrm{STV}$ patients $(15.4 \%)$, and 2 NSTV patients $(28.6 \%)$. None of the patients with the LIV chosen at SV needed distal extension due to adding on.

Conclusions: The more cranial the selection of the LIV above the SV, the higher the risk of adding on and of revision surgery with distal extension during follow up. Saving motion segments could be justified by choosing STV as LIV because the need for distal extension is not high, and it can be scheduled during lengthening procedures or at graduation surgery.
\end{abstract}

Level of Evidence: 4.

Clinical Relevance: Choosing the correct LIV in TGR index surgery is crucial to have a secure distal foundation, control and correct the deformity during growth, and save distal segments to allow growth and mobility.

Other \& Special Categories

Keywords: traditional growing rods, index surgery, early onset scoliosis, level selection, lower instrumented vertebra, pediatric spine deformity

\section{INTRODUCTION}

Early onset scoliosis (EOS) is a very challenging condition of the spine due to spine immaturity. The challenge of residual growth remaining in the context of an aggressive spinal deformity that needs spinal stabilization and guidance. Several etiologic factors can be implicated in this condition such as congenital malformations, neuromuscular or syndromic diseases, or idiopathic conditions. The presence of a growing spine could lead to major deformity after skeletal maturity, with potential cardiopulmonary compromise if not treated. ${ }^{1}$
Traditional growing rods (TGRs) are a useful tool to treat these patients when the severity of the curves does not allow any further conservative treatment. ${ }^{2,3}$ TGRs can correct the spinal deformity and guide subsequent spinal growth with a program of serial lengthenings. At the same time, they allow thoracic and trunk growth until skeletal maturity is achieved. ${ }^{4}$ Limitations of the technique include the law of diminishing returns, ${ }^{5}$ the risk of proximal junctional kyphosis, ${ }^{6}$ implant failure, ${ }^{7}$ and a reoperation rate of $15 \% .^{8}$

Despite a wide international experience with TGR, there are still no consensus criteria on how 
to select the lower instrumented vertebra (LIV) at index surgery. Similar to what is done in adolescent idiopathic scoliosis (AIS) surgery, surgeons try to be as selective as possible with the instrumentation and save as many distal mobile segments as possible. ${ }^{9}$ The criteria followed in AIS fusion is based on the stable vertebra (SV), the vertebra substantially touched by the central sacral vertical line (STV), and the vertebra tangentially touched (not substantially touched) by the line (NSTV). Reports have highlighted that, ideally, LIV in AIS should aim to be the STV, which allows us to save distal segments with a low risk of subsequent failures. ${ }^{10-12}$ However, this criterion might not fit for EOS treated with TGR because growth and curve progression might add distal segments to the original curve (adding-on effect). The fate of the LIV in a spine with remaining residual growth, which undergoes serial lengthenings is still underexplored.

The aim of our study was to evaluate whether the criteria used for AIS-operated patients to select the LIV adapts to EOS patients treated with TGRs.

\section{MATERIALS AND METHODS}

This is a retrospective cohort study of prospectively longitudinal collected data.

All consecutive patients affected by EOS and treated at our institution between 2003 and 2016 with TGR were recruited in the current study. All included patients underwent index surgical treatment with traditional dual growing rods with proximal and distal spine-based foundations using pedicle screws or hooks and rods connected by sideto-side wedding bands and had a minimum 2-year follow up postgraduation. Graduation was defined as the end of the distraction treatment and was followed either by implant retention and further observation or by final fusion.

Patients with incomplete radiological data, those lost at follow up, those with distal foundation at the sacrum or pelvis, patients treated with other types of growth-friendly techniques, or without a minimum 2-year follow up after graduation were excluded from our study.

Demographic data such as age, gender, and etiology of scoliosis were recorded.

\section{Radiographic Measurements}

Radiographic analysis included standing posterior-anterior and lateral radiographs on different stages: preoperative, immediate postoperative, at graduation, and at final follow up. In some cases, preoperative coronal and lateral traction films were available. One of the authors not involved in the operating team performed all radiographic measurements.

On preoperative radiographs, the following parameters were analyzed: the magnitude of the major curve assessed by the Cobb angle on standing and on traction radiographs, coronal balance, the location of the SV, the STV, the NSTV, and the SV tilt.

Instrumentation data were recorded on postoperative radiographs: type of distal construct (pedicle screws or hooks) and number of vertebrae included in the distal foundation.

Major curve Cobb angle on standing radiographs, coronal balance, the LIV, LIV tilt, disc wedge below LIV, disc wedge 1 level below LIV, and the distal junctional angle (DJA) were calculated on immediate postoperative, graduation, and follow-up radiographs. The value of DJA was reported as positive if the segment was in kyphosis and negative if the segment was in lordosis. Age and Risser stage at the moment of graduation were also recorded.

The SV was considered as the vertebra most closely bisected by the central sacral vertical line (CSVL) defined by King et al. ${ }^{13}$ The STV was considered as the vertebra in which the CSVL fell out of the medial border of the pedicle of the vertebra, and the NSTV was considered when the CSVL fell lateral to the external border of the pedicle. ${ }^{14}$

The team of surgeons involved in the cases are dedicated deformity spine surgeons led by the last author who has more than 40 years of experience in pediatric spine deformity. The level chosen for LIV was selected case by case and based on the classical criteria of the stable distal zone. Therefore, the LIV was selected at a level at or below the end vertebra, which needed to be closely touched by the CSVL and have little or no rotation (neutral vertebra). Our study analyzes if that decision was correct. Failure of LIV selection was considered when revision surgery for distal extension was needed due to adding on. Adding on was defined as a difference of more than $10^{\circ}$ between LIV tilt on the immediate postoperative and the follow-up radiographs. 
Table 1. Main demographic and preoperative radiological data.

\begin{tabular}{ll}
\hline Parameter & \\
\hline Patients & \\
Age, mean $\pm \mathrm{SD}, \mathrm{y}$ & $8.56 \pm 3.01$ \\
$\quad$ Males & 6 \\
$\quad$ Females & \\
Type of scoliosis & 9 \\
$\quad$ Idiopathic & 8 \\
$\quad$ Syndromic & 5 \\
Neuromuscular & 2 \\
$\quad$ Secondary to Askin tumor & 19 \\
$\quad$ Congenital & $78.8 \pm 15.37$ \\
Cobb angle on standing x-ray, mean $\pm \mathrm{SD}{ }^{\circ}$ & $18.3 \pm 18.61$ \\
Coronal balance on standing X-ray, mean $\pm \mathrm{SD}, \mathrm{mm}$ & $\mathrm{L} 5(10 / 25), \mathrm{L} 4(6 / 25), \mathrm{L} 3(5 / 25), \mathrm{L} 2(2 / 25), \mathrm{L} 1(1 / 25), \mathrm{T} 12(1 / 25), \mathrm{T} 11(1 / 25)$ \\
Most frequent stable vertebra & $\mathrm{L} 4(9 / 25), \mathrm{L} 3(5 / 25), \mathrm{L} 2(4 / 25), \mathrm{L} 1(1 / 25), \mathrm{T} 12(1 / 25), \mathrm{T} 11(1 / 25)$ \\
Most frequent STV & $\mathrm{L} 3(8 / 25), \mathrm{L} 2(3 / 25), \mathrm{L} 1(1 / 25)$ \\
Most frequent NSTV & $45.5 \pm 15.15$ \\
Cobb angle on traction x-ray, mean $\pm \mathrm{SD},{ }^{\circ}$ & $46.18 \pm 12.72$ \\
Reduction in traction, mean $\pm \mathrm{SD}, \%$ & $3.24 \pm 1.2$ \\
Risser at graduation, mean $\pm \mathrm{SD}$ & $15.12 \pm 1.81$ \\
Age at graduation, mean $\pm \mathrm{SD}, \mathrm{y}$ & $105.6 \pm 32.74$ \\
Follow up from index surgery, mean $\pm \mathrm{SD}$, mo & $27.76 \pm 12.59$ \\
Follow up after graduation, mean $\pm \mathrm{SD}$, mo & \\
\hline
\end{tabular}

Abbreviations: NSTV, not substantially touched vertebra; SD, standard deviation; STV, substantially touched vertebra.

\section{Statistical Methods}

Data were expressed as mean \pm standard deviation for quantitative variables or percentage for qualitative variables. Most frequent SV, STV, NSTV, and LIV were reported as modal distribution. The analysis was performed through STATA13 software (StataCorp LLC, College Station, Texas). Student $t$ test was used to find differences between quantitative variables, and $P$ value of $<.05$ was considered statistically significant.

\section{RESULTS}

Twenty-five EOS patients met inclusion criteria. Mean age at the beginning of treatment was $8.6 \pm 3$ years, $15.1 \pm 1.8$ years at graduation, and $17.8 \pm$ 1.6 years at final follow up. Eleven patients had single thoracic deformities, 6 had thoracolumbar curves, and 8 had double curves.

The most important demographic and preoperative radiological data are reported in Table 1.

The etiology of the deformities was diverse: 8 were idiopathic curves with no additional comorbidities, and 1 had an idiopathic curve with a previously operated interauricular communication. Eight patients had syndromic scoliosis: 2 suffered osteogenesis imperfecta, 1 Di George syndrome, 1 spondylothoracic syndrome, 1 Noonan syndrome, 1 Smith-Magensis syndrome, 1 Poland syndrome, and the last one had an unspecific psychomotor delay. Five patients had neuromuscular scoliosis (1 suffered a nemalinic myopathy). Two patients devel- oped progressive scoliosis after surgical resection of an Askin tumor, and 1 had congenital scoliosis with an associated renal malformation.

In single thoracic curves, the most frequent $\mathrm{SV}$ was L3 (5/11) followed by L4 (2/11), L5, L2, L1, and T12 (1/11 each); the most frequent STV was L2 (6/ 11), followed by L3 (2/11), L4, L1, and T11 (1/25 each); while no prevalence was recorded for NSTV: L1, L2, and L3 were recorded 1 time each.

In thoracolumbar curves, no prevalence for $\mathrm{SV}$ was recorded, L4 and L5 (3/6 each); the most frequent STV was L4 (3/6) followed by L3 (2/6); while most frequent NSTV was L3 (3/6 cases)

In double curves, the most frequent $\mathrm{SV}$ was L5 (6/8) followed by L2 and L4 (1/8 each); the most frequent STV was L4 (5/8) followed by L3 and L1 (1/8 each); and the most frequent NSTV was L3 (4/ 8) followed by L2 (1/8).

Overall, considering both single and double curves, the global most frequent SV was L5 (10/ 25); the most frequent STV was L4 (9/25); and the most frequent NSTV was L3 $(8 / 25)$.

Immediately after operation, the most frequent LIV was L3 (13/25) followed by L2 (6/25), L4 (3/ 25), L1 (2/25), and L5 (1/25). Looking at the preoperative standing radiographs, the STV was selected as LIV in $13 / 25$ cases, the NSTV in $7 / 25$ cases, and the SV in $5 / 25$ cases. The mean postoperative LIV tilt was $10.37^{\circ} \pm 6.71^{\circ}$. Pedicle screws were the preferred distal anchors used to secure the distal foundation. The mean number of lower instrumented levels was $2.04 \pm 0.2$. 


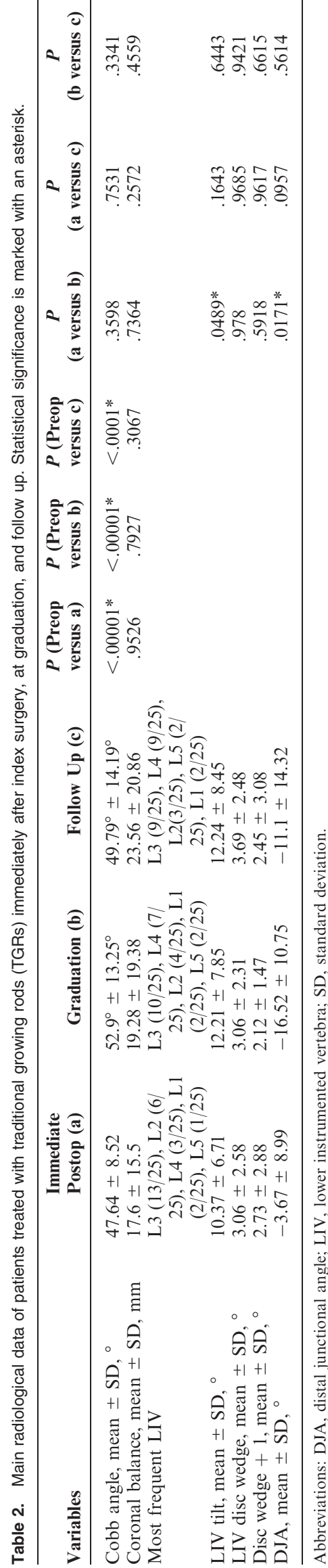

At graduation, the most frequent LIV was still L3 $(10 / 25)$, with a mean LIV tilt of $12.21^{\circ} \pm 7.85^{\circ}$, a mean LIV disc wedge of $3.06^{\circ} \pm 2.31^{\circ}$, and a mean DJA of $16.5^{\circ} \pm 10.7^{\circ}$. Ten patients were graduated with TGR retention, while 15 patients graduated with final fusion.

At final follow up, the most frequent LIV was L3 $(9 / 25)$, and the mean final LIV tilt was $11.43^{\circ} \pm$ $8.81^{\circ}$.

A summary of immediate postoperative, graduation, and follow-up data is reported in Table 2 . During the follow up until graduation, a statistically significant increase in the mean LIV tilt $(P=.049)$ and DJA $(P=.017)$ was found. A significant difference was found between preoperative and immediate postoperative Cobb angles $(P<$ $.00001)$, between preoperative and graduation Cobb angles $(P<.00001)$, and between preoperative and final follow-up Cobb angles $(P<.0001)$.

Complications are reported in Table 3. Nine patients $(9 / 25 ; 36 \%)$ suffered adding on during follow up. In 1 of them, the selected LIV was the SV $(1 / 5 ; 20 \%), 5$ of them had LIV at the STV $(5 / 13$; $38.5 \%)$, the other 3 had the LIV at NSTV (3/7; $42.8 \%)$. Four out of these $9(44 \%)$ adding-on cases (16\% of the total cohort) required surgical revision with 1 additional level of distal extension. Those patients undergoing revision surgery had a mean LIV tilt increase of $17.6^{\circ}$ compared with $11.3^{\circ}$ on those not needing distal extension. Revision surgery was performed in 2 patients with LIV at STV (2/ $13 ; 15.4 \%)$ and 2 patients with LIV at NSTV (2/7; $28.6 \%$ ). None of the patients with LIV chosen at the SV needed distal extension due to adding on.

\section{DISCUSSION}

The correct selection of the LIV in AIS when planning instrumented fusion is still under debate. Although the SV has been the classically recommended spot to safely place the distal anchors, recent literature has suggested the STV as a reasonable level to set the LIV. The STV allows a

Table 3. List of complications that occurred during observation period

\begin{tabular}{ll}
\hline Parameter & \multicolumn{1}{c}{ Value } \\
\hline Rod breakages & 6 times (3 times in the same patient) \\
Screw or anchor pull out & 6 times \\
Screw malpositioning & 1 time \\
Adding on & 9 patients \\
Proximal junctional kyphosis & 3 times \\
Distal junctional kyphosis & 1 time \\
Infection & 1 time \\
\hline
\end{tabular}




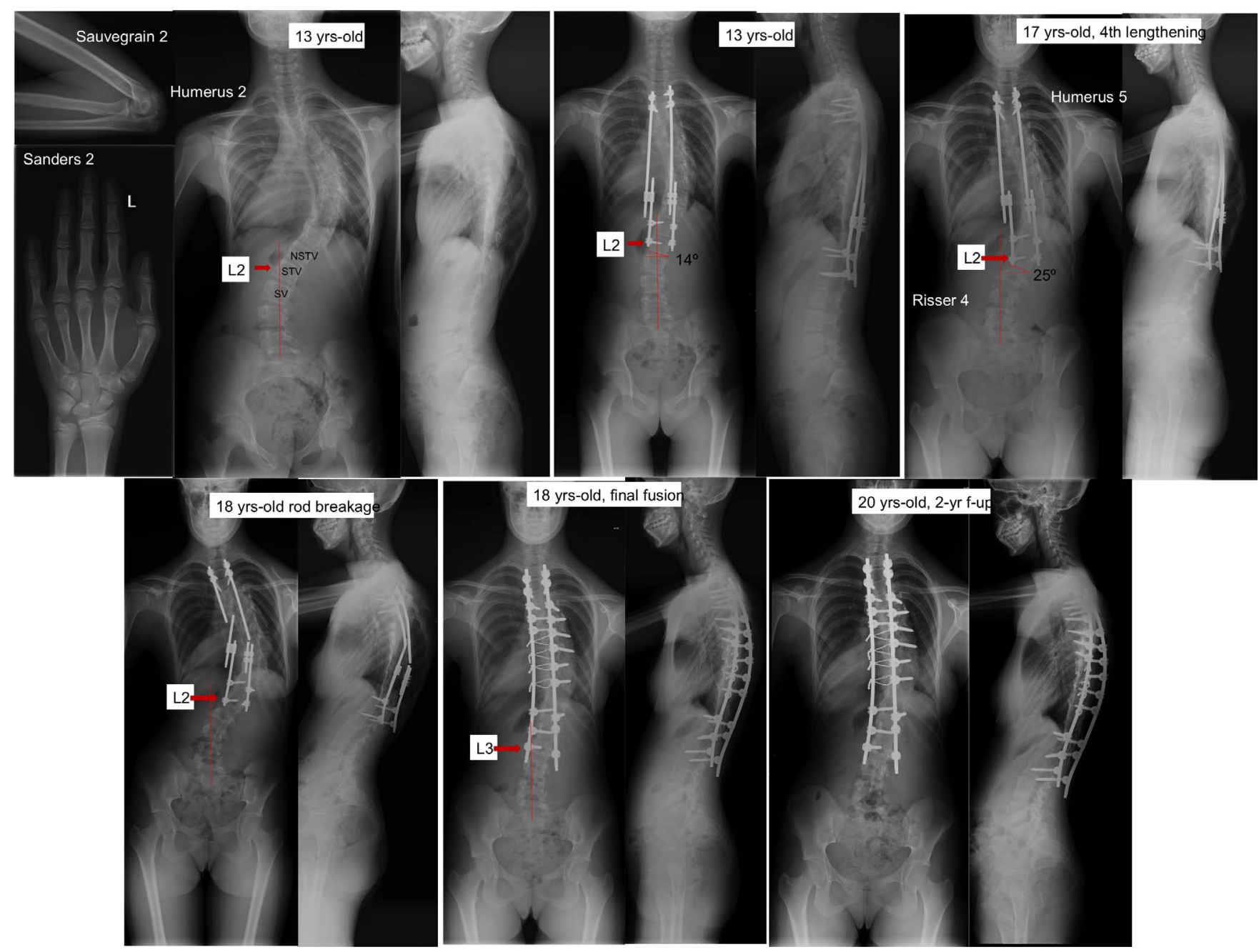

Figure 1. Idiopathic scoliosis treated with traditional growing rods. L2 was the substantially touched vertebra and was selected as the lower instrumented vertebra. After the fourth lengthening, the patient developed a distal adding on and, afterwards, a bilateral rod breakage ocurred. Posterior final fusion was performed at skeletal maturity to fix both complications and improve balance, with 1 level distal extension. The last image shows 2 -year follow up after final fusion.

good correction of the deformity, while minimizing the extension of the fusion, saving motion segments, with a small risk of distal complications. ${ }^{15-20}$ However, the decision is still in many cases driven by the surgeon's own experience. ${ }^{21}$ The situation is even more controversial for EOS; due to the potential growth remaining, long instrumentations can lead to a crankshaft phenomenon, ${ }^{22}$ and short fusions can drive to adding on. ${ }^{23}$

In these surgeries, it is then important to choose the appropriate LIV, especially in the lumbar spine, where it is known that extensive fixation affects future spinal motion. ${ }^{24,25}$ The contribution of each single level on global lumbar mobility has been shown to be variable. ${ }^{26,27}$ However, it is known that extending instrumentation below L3 may jeopardize function, increase the risk of disability, and drive adjacent segment problems. ${ }^{28}$ For that reason, saving segments could increase long-term spinal motion and preserve the quality of life in the mid and long run. ${ }^{9}$

Growth-friendly techniques, as TGR, are commonly used to control pediatric spinal deformity while still allowing spinal growth. However, after several lengthenings, the correction potential of this technique diminishes due to autofusion of the segments between the upper and lower anchorage points. ${ }^{29}$ The shorter the extension of the instrumentation, the fewer the segments for potential autofusion. In this scenario, Dede et $\mathrm{al}^{9}{ }^{9}$ recommended stopping at "stable to be" vertebra (StbV) in TGR, which is the SV on traction films. Despite this first attempt to recommend the LIV in TGR, there are still no consensus criteria on where to select the LIV at index surgery and what the fate of it is. 


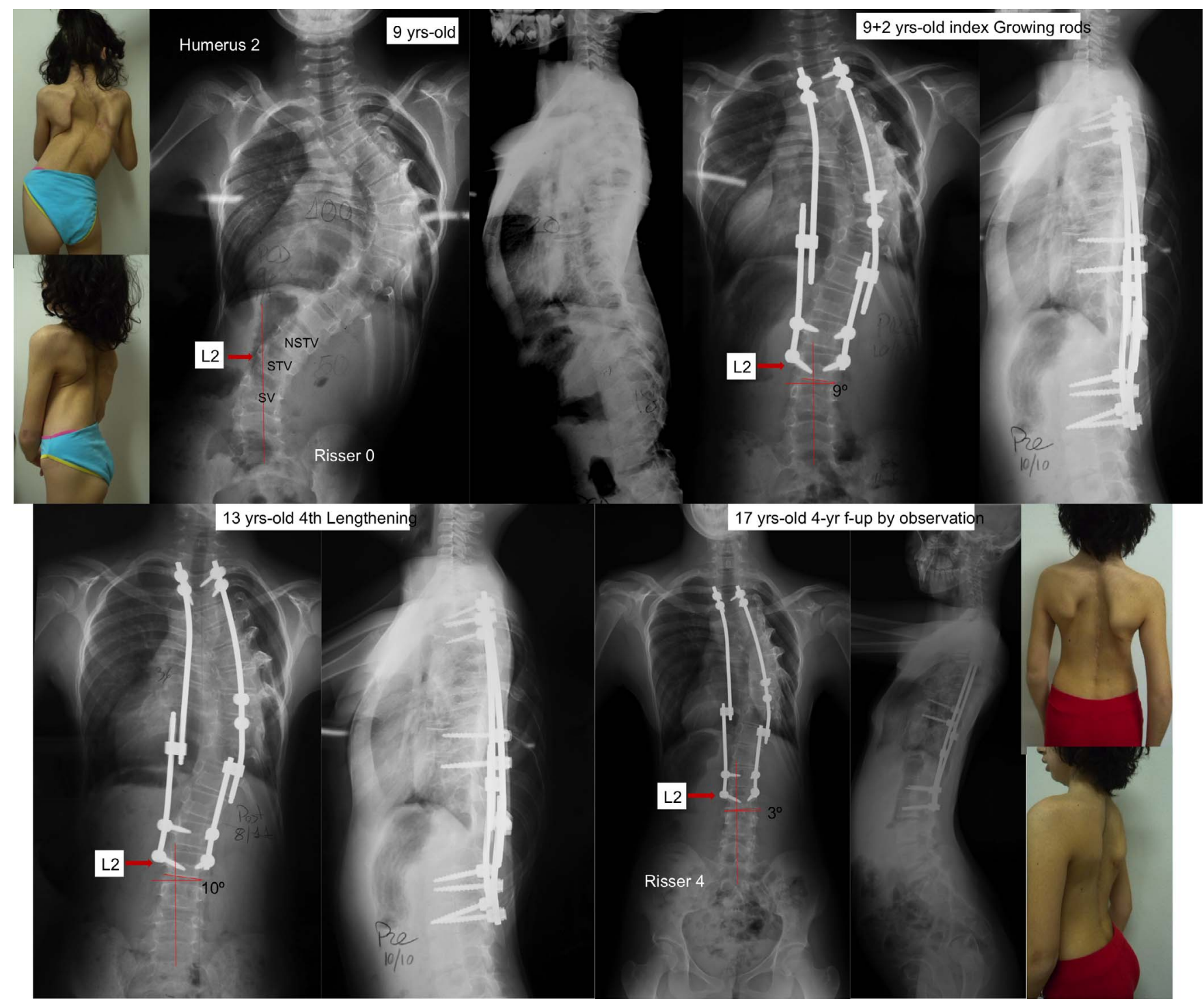

Figure 2. Nine-year-old female patient who developed a thoracic curve months after a wide rib resection secondary to an Askin tumor. Traditional growing rods were implanted, choosing the lower instrumented vertebra at L2, which corresponded to the substantially touched vertebra. After the fourth lengthening, we decided to stop distractions, and the patient was followed with observation. Additional 4-year follow up with no adding on.

In our study, the most common LIV was L3, and only $16 \%$ of our cohort was instrumented at or below L4. The STV was our preferred choice followed by NSTV, meaning that we were guided by the concept of saving distal levels. Only $20 \%$ of our cases were instrumented at the SV. We have chosen a mean of 2 distal levels as our secure foundation.

Along follow up, we detected a LIV tilt increase over $10^{\circ}$ in $36 \%$ of our patients; they were considered as having a radiographic adding on. The risk of this complication was $20 \%$ if the LIV was the SV, 38\% if the STV was chosen, and $43 \%$ if the NSTV was chosen. Thus, the more cranial the LIV, the higher the risk for adding on. Eventually,
$44 \%$ of them needed revision surgery with an additional level of distal extension to address this complication. The drivers for distal extension were an excessive LIV tilt (mean increase of $17.6^{\circ}$ ), coronal imbalance, and translational LIV shift falling lateral to the CSVL. This constituted a final rate of $16 \%$ of the total cohort needing distal extension due to adding on after 9 years of follow up (Figure 1). From these 4 extended patients, 2 corresponded to patients with initial LIV at the STV $(15.4 \%)$ and 2 at the NSTV $(28.6 \%)$. At the end of follow up, none of the patients who were initially stopped at the SV needed surgical extension. 
Over the course of treatment, lengthenings could control coronal deformity magnitude and coronal alignment. However, controlling the sagittal plane had its issues; the DJA increased a mean of $16^{\circ}$, and 3 patients needed revision surgery due to screw pull out. When comparing these results with major series, ${ }^{30,31}$ we found similar effectiveness in coronal correction but higher rates of adding on and distal extension in our cohort. Rod breakage and anchor pull out are the most reported complications in the literature. ${ }^{32}$ Severe EOS curves show more complications than moderate deformities. ${ }^{33,34}$

To the best of our knowledge, this is the first study analyzing the rate of adding on related to LIV selection in a long-term follow up of patients treated with TGR in EOS. Choosing the STV as the LIV in TGR index surgery, which is generally 1 level above the SV, can preserve motion segments with a low risk of further distal extension (Figure 2). Distal revision, if needed, can be performed during scheduled procedures. Selecting NSTV has a higher risk of adding on along the course of treatment.

Several limitations to this study must be acknowledged. Some are intrinsic to the retrospective nature of the study, the low number of patients, and the lack of a control group and patients' randomization. Moreover, a priori sample size calculation was not performed, and the lack of power did not allow a statistical comparison between LIV and rate of adding on. We were also limited by the low number of studies reporting on the selection of LIV in EOS. The strength of the study relies on a long follow up. We have followed the patients throughout 9 years, beginning with an age of 8 , analyzed at graduation, and even 2 years after that.

\section{CONCLUSIONS}

In TGR index surgery, the more cranial the selection of the LIV above the SV, the higher the risk of adding on and of revision with distal extension during treatment. Saving motion segments could be justified by choosing STV as LIV because the need for distal extension is not high, and it can be scheduled during lengthening procedures or at graduation surgery.

\section{REFERENCES}

1. Mayer O, Campbell R, Cahill P, Redding G. Thoracic insufficiency syndrome. Curr Probl Pediatr Adolesc Health Care. 2016;46(3):72-97. doi:10.1016/j.cppeds.2015.11.001

2. Mao S, Sun X, Shi B, et al. Association between braced curve behavior by pubertal growth peak and bracing effectiveness in female idiopathic scoliosis: a longitudinal cohort study. BMC Musculoskelet Disord. 2018;19(1):88. doi:10.1186/s12891018-1987-9

3. Waldron SR, Poe-Kochert C, Son-Hing JP, Thompson GH. Early onset scoliosis: the value of serial Risser casts. $J$ Pediatr Orthop. 2013;33(8):775-780. doi:10.1097/BPO. 0000000000000072

4. Skaggs DL, Akbarnia BA, Flynn JM, et al. A classification of growth friendly spine implants. $J$ Pediatr Orthop. 2014;34(3):260-274. doi:10.1097/BPO. 0000000000000073

5. Sankar WN, Skaggs DL, Yazici M, et al. Lengthening of dual growing rods and the law of diminishing returns. Spine (Phila Pa 1976). 2011;36(10):806-809. doi:10.1097/BRS. 0b013e318214d78f

6. El-Hawary R, Samdani A, Wade J, et al. Rib-based distraction surgery maintains total spine growth. $J$ Pediatr Orthop. 2016;36(8):841-846. doi:10.1097/BPO. 0000000000000567

7. Erdoğan S, Polat B, Atıcı Y, et al. Comparison of the effects of magnetically controlled growing rod and traditional growing rod techniques on the sagittal plane in the treatment of early-onset scoliosis. J Korean Neurosurg Soc. 2019;62(5):577585. doi:10.3340/jkns.2019.0094

8. Cheung JPY, Yiu K, Kwan K, Cheung KMC. Mean 6year follow-up of magnetically controlled growing rod patients with early onset scoliosis: a glimpse of what happens to graduates. Neurosurgery. 2019;84(5):1112-1123. doi:10.1093/ neuros/nyy270

9. Dede O, Demirkiran G, Bekmez S, et al. Utilizing the "stable-to-be vertebra" saves motion segments in growing rods treatment for early-onset scoliosis. $J$ Pediatr Orthop. 2016;36(4):336-342. doi:10.1097/BPO.0000000000000467

10. Bai J, Chen K, Wei Q, et al. Selecting the LSTV as the lower instrumented vertebra in the treatment of Lenke types 1A and 2A adolescent idiopathic scoliosis. Spine (Phila Pa 1976). 2018;43(7):E390-E398. doi:10.1097/BRS.0000000000002375

11. Cao K, Watanabe K, Kawakami N, et al. Selection of lower instrumented vertebra in treating Lenke type $2 \mathrm{~A}$ adolescent idiopathic scoliosis. Spine (Phila Pa 1976). 2014;39(4):E253-E261. doi:10.1097/BRS.0000000000000126

12. Ketenci I, Yanik H, Ulusoy A, et al. Lowest instrumented vertebrae selection for posterior fusion of Lenke $5 \mathrm{C}$ adolescent idiopathic scoliosis: can we stop the fusion one level proximal to lower-end vertebra? Indian J Orthop. 2018;52(6):657-664. doi:10.4103/ortho.IJOrtho_579_16

13. King HA, Moe JH, Bradford DS, Winter RB. The selection of fusion levels in thoracic idiopathic scoliosis. $J$ Bone Joint Surg Am. 1983;65(9):1302-1313.

14. Qin X, Sun W, Xu L, et al. Selecting the last "substantially" touching vertebra as lowest instrumented vertebra in Lenke type 1A curve. Spine (Phila Pa 1976). 2016;41(12):E742-E750. doi:10.1097/BRS.0000000000001374

15. Lenke LG, Betz RR, Haher TR, et al. Multisurgeon assessment of surgical decision-making in adolescent idiopathic scoliosis curve classification, operative approach, and fusion levels. Spine (Phila Pa 1976). 2001;26(21):2347-2353. doi:10. 1097/00007632-200111010-00011

16. Lenke LG, Betz RR, Harms J, et al. Adolescent idiopathic scoliosis. A new classification to determine extent 
of spinal arthrodesis. J Bone Jt Surg. 2001;83(8):1169-1181. doi:10.2106/00004623-200108000-00006

17. Lenke LG, Betz RR, Bridwell KH, et al. Spontaneous lumbar curve coronal correction after selective anterior or posterior thoracic fusion in adolescent idiopathic scoliosis. Spine (Phila Pa 1976). 1999;24(16):1663-1672. doi:10.1097/ 00007632-199908150-00007

18. Lenke LG, Betz RR, Clements D, et al. Curve prevalence of a new classification of operative adolescent idiopathic scoliosis: does classification correlate with treatment? Spine (Phila Pa 1976). 2002;27(6):604-611. doi:10.1097/00007632200203150-00008

19. Lenke LG. The Lenke classification system of operative adolescent idiopathic scoliosis. Neurosurg Clin $N \mathrm{Am}$. 2007;18(2):199-206.

20. Lenke LG, Edwards CC, Bridwell KH. The Lenke classification of adolescent idiopathic scoliosis: how it organizes curve patterns as a template to perform selective fusions of the spine. Spine (Phila Pa 1976). 2003;28(20):S199-S207. doi:10. 1097/01.brs.0000092216.16155.33

21. Vitale MG, Gomez JA, Matsumoto H, et al. Variability of expert opinion in treatment of early-onset scoliosis. Clin Orthop Relat Res. 2011;469(5):1317-1322. doi:10.1007/s11999010-1540-0

22. Murphy RF, Mooney JF. The crankshaft phenomenon. J Am Acad Orthop Surg. 2017;25(9):e185-e193. doi:10.5435/ JAAOS-D-16-00584

23. Zang L, Hai Y, Yuan S, et al. Distal adding-on and risk factors in severe and rigid scoliosis. Spine (Phila Pa 1976). 2017;42(3):160-168. doi:10.1097/BRS.0000000000001684

24. Udoekwere UI, Krzak JJ, Graf A, et al. Effect of lowest instrumented vertebra on trunk mobility in patients with adolescent idiopathic scoliosis undergoing a posterior spinal fusion. Spine Deform. 2014;2(4):291-300. doi:10.1016/j.jspd. 2014.04.006

25. Wilk B, Karol LA, Johnston CE, et al. The effect of scoliosis fusion on spinal motion: a comparison of fused and nonfused patients with idiopathic scoliosis. Spine (Phila $\mathrm{Pa}$ 1976). 2006;31(3):309-314. doi:10.1097/01.brs.0000197168. 11815.ec

26. Gercek E, Hartmann F, Kuhn S, et al. Dynamic angular three-dimensional measurement of multisegmental thoracolumbar motion in vivo. Spine (Phila Pa 1976). 2008;33(21):23262333. doi:10.1097/BRS.0b013e31818096ea

27. Ochia RS, Inoue N, Renner SM, et al. Threedimensional in vivo measurement of lumbar spine segmental motion. Spine (Phila Pa 1976). 2006;31(18):2073-2078. doi:10. 1097/01.brs.0000231435.55842.9e

28. Ilharreborde B, Morel E, Mazda K, Dekutoski MB. Adjacent segment disease after instrumented fusion for idiopathic scoliosis: review of current trends and controversies. J Spinal Disord Tech. 2009;22(7):530-539. doi:10.1097/BSD. 0b013e31818d64b7

29. Flynn JM, Tomlinson LA, Pawelek J, et al. Growing-rod graduates: lessons learned from ninety-nine patients who completed lengthening. J Bone Joint Surg Am. 2013;95(19):1745-1750. doi:10.2106/JBJS.L.01386

30. Akbarnia BA, Marks DS, Boachie-Adjei O, et al. Dual growing rod technique for the treatment of progressive earlyonset scoliosis: a multicenter study. Spine (Phila Pa. 1976). 2005;30(17 Suppl):S46-S57.

31. Akbarnia BA, Emans JB. Complications of growthsparing surgery in early onset scoliosis. Spine (Phila Pa 1976). 2010;35(25):2193-2204. doi:10.1097/BRS.0b013e3181f070b5

32. Thompson GH, Akbarnia BA, Campbell RM. Growing rod techniques in early-onset scoliosis. $J$ Pediatr Orthop. 2007;27(3):354-361. doi:10.1097/BPO.0b013e3180333eea

33. Helenius IJ, Oksanen HM, McClung A, et al. Outcomes of growing rod surgery for severe compared with moderate early-onset scoliosis: a matched comparative study. Bone Joint J. 2018;100B(6):772-779. doi:10.1302/0301-620X.100B6.BJJ2017-1490.R1

34. Upasani VV, Parvaresh KC, Pawelek JB, et al. Age at initiation and deformity magnitude influence complication rates of surgical treatment with traditional growing rods in earlyonset scoliosis. Spine Deform. 2016;4(5):344-350. doi:10.1016/j. jspd.2016.04.002

Disclosures and COI: The authors declare they have no conflict of interest related to the topic of the study. No grants or funds were received for this project. No benefits in any form have been or will be received from a commercial party related directly to the subject of this manuscript. This study has institutional review board or research ethics committee approval. The study procedures were in accordance with the ethical standards of the responsible committee on human experimentation (institutional and national) and with the Helsinki Declaration of 1975, as revised in 2000. All patients gave their informed consent in participating in the study and publication of the results.

Corresponding Author: Javier Pizones, MD, $\mathrm{PhD}$, Department of Orthopaedic Surgery, Hospital Universitario La Paz, Paseo de la Castellana 261 28046. Madrid, Spain. Phone: 0034616644876; Fax: 0034913591351; Email: javierpizones@gmail.com.

Published 1 June 2021

This manuscript is generously published free of charge by ISASS, the International Society for the Advancement of Spine Surgery. Copyright (C) 2021 ISASS. To see more or order reprints or permissions, see http://ijssurgery.com. 